\title{
Alfredo Gallis (1859-1910), pequeno naturalista
}

\author{
Alfredo Gallis (1859-1910), minor \\ naturalist
}

Leonardo Mendes

Universidade do Estado do Rio de Janeiro

\begin{abstract}
Aline Moreira
Universidade do Estado do Rio de Janeiro

Universidade da Califórnia, Santa Bárbara
\end{abstract}

\section{DoI}

https://doi.org/10.37508/rcl.2021.n46a 458

\section{RESUMO}

O trabalho apresenta a trajetória do escritor naturalista português Joaquim Alfredo Gallis (1859-1910). Homem de letras famoso no final do século XIX e início do XX, Gallis faz parte de uma geração de escritores profissionais que transitava entre a literatura e a imprensa. Publicou dezenas de volumes de contos, assinando com o próprio nome ou com pseudônimos, além de participar ativamente nos principais periódicos da época, escrevendo em prosa e verso. Atuou na administração pública e tinha vínculos com a realeza. Mas nem o vulto da atuação como escritor nem a posição social garantiram a Alfredo Gallis um lugar na história da literatura. Ainda em vida, "manchou" sua imagem por escrever pornografia, principalmente a que assinava com o pseudônimo "Rabelais". A história de Alfredo Gallis, aqui reescrita a partir de pesquisas recentes, revela um polígrafo capaz de atuar em vários gêneros e estilos textuais. 
Chamamos o escritor de "pequeno naturalista", no sentido de que foi rebaixado e esquecido pelos contemporâneos e pela história. Influenciado pelo naturalismo e pelo romance libertino, Gallis escrevia livros para serem lidos por um público amplo, que reconhecia nele um dos escritores mais importantes da cena literária da Belle Époque luso-brasileira.

Palavras-chave: Literatura luso-brasileira. Naturalismo. Belle Époque. Alfredo Gallis.

\section{Abstract}

This work presents the trajectory of the Portuguese naturalist writer Joaquim Alfredo Gallis (1859-1910). A famous man of letters in the late 19th and early 2oth centuries, Gallis is part of a generation of professional writers who moved between literature and the press. He published dozens of volumes of short stories, signing with his own name or pseudonyms, had an active role in the main periodicals of the time, writing prose and verse. He served in public administration positions and had ties to the royalty. But neither the importance of his role as a writer nor his social position guaranteed Alfredo Gallis a place in the history of literature. While still alive, he "smeared" his image by writing pornography, especially the one he signed with the pseudonym "Rabelais". The story of Alfredo Gallis, here rewritten based on recent research, reveals a polygraph capable of working in various genres and textual styles. We call the writer a "minor naturalist" in the sense that he was demoted and forgotten by contemporaries and history. Influenced by naturalism and the libertine novel, Gallis wrote books to be read by a wide audience, which recognized in him one of the most important characters in the literary scene of the Luso-Brazilian Belle Époque.

KEYWORDS: Luso-Brazilian literature. Naturalism. Alfredo Gallis.

Joaquim Alfredo Gallis foi um dos escritores mais ativos e célebres no circuito literário luso-brasileiro da Belle Époque. Nascido em Lisboa em 1859 e morto na mesma cidade em 1910, aos 51 anos, Alfredo Gallis, como era conhecido, escreveu mais de quarenta obras ao longo de trinta anos de uma carreira literária fecunda e comercialmente bem-sucedida. Como outros escritores do período, ele foi um polígrafo que atuava simultaneamente em vários fóruns de escrita e gêneros textuais. Sabia compor versos e chegou a publicar sonetos 
em periódicos, mas foi nos gêneros em prosa que exibiu sua extraordinária capacidade de criar histórias e compor milhares de páginas de ficção, em dezenas de romances e volumes de contos. Na virada do século, os livros de Gallis circulavam aos milhares pelas livrarias portuguesas e brasileiras. Seu nome e pseudônimos povoavam os periódicos e eram destaque nos anúncios de livrarias (ALMEIDA, 2018). Numa crônica de 1905, João do Rio destacou Alfredo Gallis como um escritor em demanda na Biblioteca Nacional, numa lista que incluía Émile Zola e José de Alencar (Gazeta de notícias, o6/02/1905, p. 6). Até a década de 1930 seu nome circulava nas livrarias como autor conhecido e procurado (MENDES; MOREIRA, 2019). A partir de então, começou a desaparecer. Hoje seus livros são raridades bibliográficas.

Há várias explicações para o apagamento de Alfredo Gallis. Massaud Moisés (1994) julga seus romances naturalistas inverossímeis. Para o crítico, o naturalismo era uma estética equivocada. Com diagnóstico semelhante de insuficiência, Maria Helena Santana (2007) assinala a falta de qualidade estética das obras como razão do esquecimento. Pedro Pavão dos Santos (2014) aponta para razões extraliterárias, como as simpatias monarquistas do escritor, que era ligado a membros da realeza portuguesa. Em tempos de fervor republicano, a monarquia era associada ao passado e ao obscurantismo. Tal posicionamento possivelmente o isolava entre os homens de letras, em sua maioria republicanos. As razões para o desaparecimento dos livros físicos são mais prosaicas. Populares, baratos e descartáveis, os livros de Gallis eram impressos em material de baixa qualidade e por isso a maior parte virou pó. Não conhecemos biblioteca pública que tenha sua obra completa. Mas sem dúvida o maior problema para a memória do escritor foi seu vínculo com a pornografia, com os chamados "livros para homens", um filão lucrativo do mercado editorial do período que ele explorou e ajudou a desenvolver (EL FAR, 2004; MENDES, 2016; SANTANA, 2007). Para Roberto Ventura (2011), numa reedição recente de contos eróticos 
de Gallis, a proximidade com a pornografia manchou, ainda em vida, sua reputação de artista.

Neste trabalho vamos contar a história de Alfredo Gallis. Propomos nomeá-lo "pequeno naturalista”. A expressão foi criada em 1883 pelo crítico francês Ferdinand Brunetière para designar escritores naturalistas menos conhecidos, como Paul Alexis e Henri Céard, que não estavam à altura do mestre Zola e dos irmãos Goncourt (BECKER; DUFIEFF, 200o). Ao chamar esses escritores de "pequenos", o crítico oitocentista buscava desqualificá-los e rebaixá-los. Neste trabalho, entretanto, o adjetivo não estabelece hierarquias entre mestres e discípulos, autores "maiores" e "menores", mas, ao contrário, busca descrever e problematizar o lugar subalterno de Alfredo Gallis nas letras luso-brasileiras, no seu tempo e na posteridade, associado a um gênero "baixo" e malvisto como a pornografia, sem a circunspecção e as qualidades estéticas esperadas de um "escritor autêntico". Naturalista porque, apesar de sua trajetória marcada pela poligrafia, o naturalismo era a estética dominante no fim do século XIX e foi o ideário que ele abraçou nos prefácios das obras, defendendo os mesmos princípios materialistas e científicos nos artigos de jornais e desenvolvendo-os na ficção. Alfredo Gallis é um "pequeno naturalista" no sentido de que foi rebaixado pelos escritores da elite letrada e pela historiografia canônica.

Nossas fontes são estudos produzidos a partir de pesquisas recentes sobre Alfredo Gallis e, sobretudo, dados coletados na imprensa periódica da virada do século XIX ao XX e consultados online em hemerotecas digitais brasileiras e portuguesas. Vamos reunir o que sabemos de sua biografia e de sua passagem pelos jornais oitocentistas. Em seguida, vamos conhecer sua trajetória de escritor e analisar as dimensões mais conhecidas de sua produção e pseudônimos. Começaremos com as obras que Alfredo Gallis assina com o próprio nome: 1. Romances naturalistas científicos, na esteira de Émile Zola; 2. Romances naturalistas sensacionalistas, que flertam abertamente 
com o escândalo e a pornografia; e 3. Fantasias eróticas do mundo antigo, que reúnem contos e romances picantes escritos a partir da leitura de clássicos da Antiguidade. Na sequência, veremos as obras assinadas com pseudônimos: 4. Contos pornográficos assinados por Rabelais, que foi seu apelido mais popular e prolífico; e 5. Manuais de aconselhamento sexual e matrimonial para ambos os sexos, assinados com os pseudônimos Barão de Alfa e Condessa de Til. Gallis tinha mais quatro pseudônimos, sobre os quais ainda sabemos pouco e que estão, por isso, fora do escopo deste trabalho: Antony, Ulisses, Kin-Fó e Duquesa Laureana.

\section{Nota biográfica e vida jornalística}

Para um escritor popular e onipresente nas livrarias e bibliotecas luso-brasileiras do fim do século, é surpreendente que saibamos tão pouco sobre Alfredo Gallis. Sabemos que era filho de Francisco Augusto Gallis e Maria Eugênia Gonçalves Gallis, mas desconhecemos o dia exato de seu nascimento em 1859 . Não se sabe que tenha morado em outro país além de Portugal. O Jornal do Recife (21 jan. 1899, p. 1) noticiou seu casamento a 7 de janeiro de 1899 com Carmina Homem de Carvalho Brito, sobre quem não localizamos informações. Aparentemente o casal não teve filhos. Suas fotografias são raras. No Arquivo Histórico Municipal de Almada, localizamos um cartão postal publicado pela Papelaria e Tipografia de Paulo Guedes \& Saraiva na década de 1900, em Lisboa, com seu retrato e autógrafo (Figura 1). Gallis aparece bem-vestido e respeitável, sentado à mesa de trabalho segurando a pena de escritor, com o tinteiro ao lado. Quando morreu, poucos jornais divulgaram o desenlace. $O$ português $A$ capital (24 nov. 1910, p. 1) noticiou o falecimento a 24 de novembro de 1910. Alfredo Gallis morreu em casa, em Lisboa, na rua do Desterro, n. 21. Tudo o que sabemos é que a morte foi causada por "enfermidade dolorosa" (Correio paulistano, 21 dez. 1910, p. 6). O corpo do escritor foi 
sepultado no dia seguinte em jazigo particular no Cemitério do Alto de S. João, na mesma cidade.

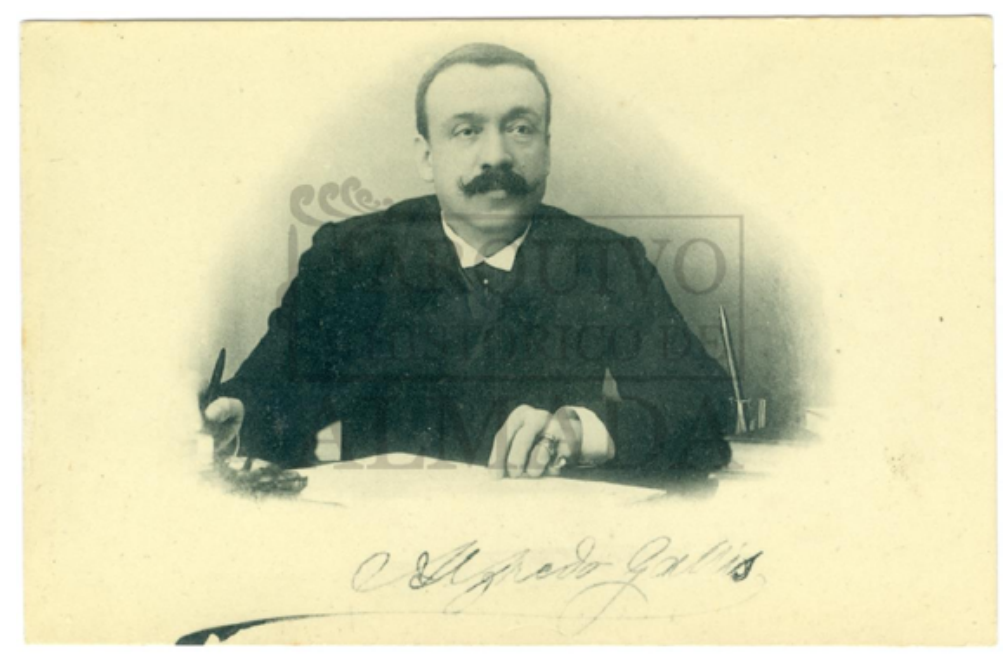

FigurA 1: Cartão Postal com retrato e autógrafo de Alfredo Gallis, década de 1900.

Fonte: Arquivo Histórico Municipal de Almada.

Alfredo Gallis pertencia à geração de escritores marcada pela "civilização do jornal” (KALIFA et al., 2011). No circuito luso-brasileiro, os periódicos se multiplicam a partir de 1870 (BARBOSA, 2010; MELLO, 2007; SODRÉ, 1984). A circulação de impressos entre o Brasil e a Europa se incrementa e diversifica (ABREU, 2016). Em razão de seu sucesso, o jornal se torna o sistema discursivo dominante (THÉRENTY, 2007). Mesmo que os escritores resistissem à comercialização da escrita e criticassem o trabalho na imprensa, a literatura se aproveita da comunicabilidade oferecida pelos jornais. As redações se transformam no principal escritório do escritor, com consequências em termos poéticos. Devido à coincidência essencial entre os dois sistemas profissionais, havia circularidade entre as formas literárias e jornalísticas. $\mathrm{O}$ escritor se profissionaliza e passa a ser remunerado pela escrita nas várias rubricas criadas pelo jornal: o folhetim, a crônica, o conto, o fait divers, a reportagem, a crítica literária, o reclame, 
a coluna satírica etc. No Brasil, escritores da geração de Gallis, como Olavo Bilac (1865-1918) e Coelho Neto (1864-1934), foram essencialmente polígrafos, com participação destacada na imprensa. Tanto a poligrafia quanto a ficção naturalista de Alfredo Gallis devem ser compreendidas nesse contexto.

O escritor iniciou a carreira jornalística em 1879, aos vinte anos, no jornal português Instituições (VENTURA, 2011). Na longa lista de periódicos em que trabalhou, estão, entre outros, o Universal, o Jornal do comércio, o Ecos da avenida, a Revista de Lisboa, O branco e o negro e o Jornal de domingo. Considerado pelos colegas de redação como um dos colaboradores de "maior comunicabilidade aos seus leitores", assinava com o pseudônimo "Antony" a coluna "Em 24 horas", do Diário Popular (ARANHA, 1911, p. 141). Para o periódico Nova alvorada: revista mensal literária e científica, Gallis escreveu ao menos três poemas, teceu elogios à memória de Camilo Castelo Branco (1825-1890) e Oliveira Martins (1845-1894), assim como criticou os "nefelibatas literários", acusando-os de ser "uma verdadeira doença literária fin de siècle", que o escritor associava a nostalgias de idealizações românticas (Nova alvorada, o1 jun. 1892, p. 133-134). Sem preocupação de produzir obra homogênea, Gallis redigia textos diversos para os periódicos: artigos de fundo e de atualidades, crítica literária e política, editoriais, poemas, matérias esportivas e traduções. O escritor exercia simultaneamente cargos públicos, como administrador municipal, escrivão dos Pilotos da Barra e secretário do governador civil de Lisboa (ALMEIDA, 2018).

Em meados da década de 1880, Gallis começa a ganhar notoriedade. Em 1885, passou a colaborar num dos periódicos portugueses mais influentes da época, $A$ ilustração portuguesa, em que também atuavam Manuel Pinheiro Chagas (1842-1985) e Guerra Junqueiro (1850-1923). Nas primeiras contribuições à revista, todas em primeira pessoa, como na crônica "O antigo Passeio Público: Lisboa contemporânea”, Alfredo Gallis parece encarnar a figura do flâneur que 
perambula pela cidade e vê em Lisboa as marcas da decadência de Portugal (A illustração portugueza, 02 mar. 1885, p. 7-8). Na imprensa brasileira, seu nome aparece pela primeira vez em 1882 nos jornais mineiros Pharol (21 nov. 1882, p. 2) e $O$ arauto de Minas (o9 dez. 1882, p. 4), assinando o folhetim "Os pombos", com o retrato da lua de mel de um casal jovem e bonito que já dava sinais de tédio sexual. Em 1887, Rafael Bordalo Pinheiro (1846-1905) o enaltece como "distinto escritor e ilustrado crítico" (Pontos nos iis, 10 dez. 1887, p. 387). Em 1892, foi correspondente do Correio paulistano, tratando dos assuntos em voga na cena portuguesa (Correio paulistano, 19 jan. 1893, p. 1). Em 1897, atuou como correspondente do monarquista Jornal do Brasil, do Rio de Janeiro (Jornal do Brasil, 30 out. 1897). Ser correspondente de um jornal estrangeiro indicava uma posição de renome, e podemos presumir que Alfredo Gallis foi um escritor proeminente no campo intelectual luso-brasileiro na Belle Époque.

\section{Naturalismo científico}

A maior parte dos romances naturalistas de Alfredo Gallis foi publicada em Lisboa nos primeiros anos do século XX. Já fazia mais de trinta anos que Zola publicara Thèrese Raquin (1867) e mais de vinte que Eça de Queirós abalara o mundo literário com $O$ crime do padre Amaro (1875) e O primo Basílio (1877). Na virada do século, essas obras ainda eram perturbadoras e continuavam a atrair controvérsia, mas tanto Zola quanto Eça de Queirós haviam defendido a seriedade do naturalismo, feito não para incentivar os hábitos corruptos da sociedade, mas para combatê-los. Os naturalistas alegavam haver uma pedagogia do "exemplo negativo" nos enredos picantes que terminavam em tragédia, como n'O primo Basílio. Ao punir a mulher adúltera com a morte, estava assegurada a moralidade da obra (SANTANA, 2015). No Brasil, Adolfo Caminha (1867-1897) usou tal argumento na defesa de Bom-Crioulo (1895), seu trágico romance 
sobre um marinheiro negro e gay. Para ele, o livro "estudava” e condenava o amor entre pessoas do mesmo sexo (MENDES, 200o). Esse modelo trágico e moralizador foi defendido pelos principais expoentes do movimento no século XIX e foi, por isso, canonizado pela historiografia, tornando-se a forma mais conhecida e respeitável de romance naturalista (MENDES; CATHARINA, 2019).

Ao compor uma série de "estudos" da sociedade portuguesa da época, Gallis se alinhava a essa concepção moralizadora de romance naturalista como retrato crítico da sociedade, com vistas ao seu aprimoramento. Na França, Zola dera o exemplo com a criação do ciclo de vinte romances sobre as trajetórias de duas famílias no Segundo Império (1852-1870), Os Rougon-Macquart, publicados entre $1871 \mathrm{e}$ 1893. No Brasil, Aluísio Azevedo criou um projeto semelhante, chamado Brasileiros antigos e modernos, do qual, contudo, só realizou O cortiço (1890). Mais perto de casa, Gallis tinha o exemplo do ciclo Patologia Social, criado por Abel Botelho (1854-1917) com o mesmo intuito de "estudar" os males da sociedade portuguesa. Na virada do século, publicara três romances: O Barão de Lavos (1891), sobre a homossexualidade; O livro de Alda (1898), sobre a prostituição; e Amanhã (1901), sobre a alienação mental (MOISÉS, 1961). O espectro da decadência da raça portuguesa paira sobre as obras. Ao conceber uma série de romances de denúncia dos males de Portugal, Gallis se apoiava nos mesmos princípios deterministas e no mesmo imaginário finissecular de degenerescência e declínio. Nessas obras, a hereditariedade e o meio exercem funções capitais no comportamento dos personagens, nas tramas e nos desfechos.

Gallis chamou sua coleção de Tuberculose social. Num intervalo de três anos, publicou, com incrível rapidez, doze romances: Chibos (1901), Os predestinados (1901), Mulheres perdidas (1902), Os decadentes (1902), Malucos (1902), Políticos (1902), Sáficas (1902), A taberna (1903), Casas de hóspedes (1903), A sacristia (1903), Mulheres honestas (1903) e Os pelintras (1904). As obras eram acompanhadas de longos 
proêmios em que o autor defende a seriedade científica e as intenções moralizadoras das narrativas, sempre apresentadas como antídotos à decadência da "raça latina". No proêmio de Chibos, numa estratégia naturalista conhecida, apoia-se na autoridade do médico e promete "autopsiar" a sociedade portuguesa nos volumes subsequentes (GALLIS, 1901, p. 5). Por sua extensão, erudição, diversidade e reverberações políticas, às vezes libertários, às vezes conservadores, os proêmios de Alfredo Gallis merecem um estudo à parte. Os títulos remetiam ao universo do naturalismo oitocentista: o anticlericalismo em A sacristia, a prostituição e o adultério em Mulheres perdidas e Mulheres honestas, o lesbianismo em Sáficas, a doença mental em Malucos, a corrupção governamental em Políticos, o crime em Os pelintras e, entre outros, o alcoolismo em A taberna, certamente inspirado no L'Assommoir (1877), de Zola.

A extensão e o detalhamento dos proêmios exprimiam o empenho de Alfredo Gallis em convencer o leitor da seriedade dos romances. $\mathrm{Na}$ virada do século, ele já contava quarenta anos de vida e vinte de carreira. Sua persona mais famosa era Rabelais, o autor de contos pornográficos. Talvez buscasse repaginar sua imagem e tornar-se respeitável junto à elite letrada, mas os romances não passavam de duzentas páginas compostas por parágrafos curtos, com pouca descrição, sem a densidade e a escala dos romances de Zola. Como painel da sociedade, mais voltada ao entretenimento e ao efeito cômico do que à crítica social, a Tuberculose social se parece mais com A comédia humana, de Honoré de Balzac (1799-1850). Havia uma disparidade entre a seriedade dos proêmios e a liberalidade dos enredos picantes, com atmosfera próxima ao burlesco ou ao romance libertino. De fato, a despeito dos proêmios doutrinadores, os romances "exploram de forma bastante libertina o deboche sexual das classes altas" (SANTANA, 2007, p. 241), sugerindo que o verdadeiro propósito de Gallis, apoiado em sua fama pregressa, era vender literatura licenciosa disfarçada de romance científico. Confirmando essa percepção, os livros 
da Tuberculose social eram anunciados como "livros para homens" pelas livrarias, às vezes junto às obras do afamado "Rabelais", que todos sabiam ser um codinome de Alfredo Gallis (ALMEIDA, 2018).

\section{Naturalismo sensacionalista}

O viés burlesco e sensacionalista do naturalismo de Alfredo Gallis fica mais evidente num grupo de romances publicados antes e depois da série Tuberculose social: Mártires da virgindade: romance patológico (1900), O marido virgem: patologia do amor (1900) e O Sr. Ganimedes: psicologia de efebo (1906). A mesma fantasia de doença e declínio aparece nos subtítulos, assim como a concepção naturalista de romance como análise das chagas sociais, mas os títulos são apelativos e cômicos. Tanto a virgindade como martírio quanto as figuras do "marido virgem" e do "efebo" desafiam códigos patriarcais de conduta da mulher e do homem. Também aqui aparecem os longos proêmios em que Gallis se declara seguidor do método de Zola, contextualiza sociologicamente cada assunto em tela e, como bom escritor naturalista, defende a moralidade das obras, mesmo que relatem condutas imorais. Os proêmios de Mártires da virgindade e d'O marido virgem são libertários e antipatriarcais. Argumentam pelo direito ao sexo da mulher sem marido e defendem que a mulher tem o mesmo direito do homem de exigir um parceiro virgem. Os enredos contam histórias trágicas causadas por fantasias patriarcais de controle da mulher, mas o estilo é satírico e libertino, em narrativas curtas e fáceis de ler, sem a gravidade dos romances de Zola.

Mártires da virgindade conta a história de Maria Manuela, uma jovem voluptuosa que tinha orgasmos quando o noivo lhe beijava as mãos. Quando o rapaz a abandona para se casar com uma viúva rica, Isabel de Albergaria, a moça entra em depressão. $\mathrm{O}$ tempo passa e a falta de sexo faz agravar os sintomas. Maria Manuela é uma das moças histéricas que animaram a pena dos naturalistas, como Magdá, 
em O homem (1887), de Aluísio Azevedo (DUARTE, 2015). Como no romance brasileiro, a moça recusa as recomendações médicas de se casar com outro homem a fim de combater a doença. Morre por complicações de um tumor uterino. O final trágico sustenta a tese do proêmio de que o celibato forçado era a verdadeira causa da histeria e só produzia loucas e cadáveres. No romance, um contraponto à mulher histérica é oferecido por Isabel de Albergaria, a antagonista de Maria Manuela. A viúva compensava a falta de parceiro com um pênis de resina chamado "Senhor Bibi", que obrigava a criada andrógina a atar na cintura e manusear. $\mathrm{O}$ trecho é tão audacioso que o narrador precisa se intrometer para assegurar a moralidade da obra. Ao narrar a cena, garante, não pretendia validar a masturbação ou o "amor sáfico", mas mostrar o que "a hipocrisia social" obrigava a mulher a fazer para acalmar os "desejos da carne" (GALLIS, s.d., p. 47).

Em $O$ marido virgem, Francelina é uma moça “excepcional, inteligente e rara" que decide se casar apenas com um rapaz puro e virgem como ela (GALLIS, s.d., p. 12). Vê no primo Gustavo, dez anos mais novo, a perfeita realização de seus objetivos. Apesar de o título focar no polo masculino, o romance é sobre Francelina e seu projeto anticonvencional. A jovem molda o rapaz aos seus desejos, vigiando-o para que se mantenha virgem para ela. Essa inversão irônica vinha de romances libertinos narrados por mulheres ilustradas, como o anônimo Teresa filósofa (1748). Em típica configuração libertina, Francelina espia o corpo nu do primo pelo buraco da fechadura e aprova suas qualidades viris. Ela é o cérebro e o cônjuge mais velho da relação. Eles se casam, vivem felizes por um tempo, mas o experimento fracassa quando se instala o tédio sexual e o rapaz sai à procura de amantes. Frágil de saúde, morre logo depois. As marcas naturalistas são a hereditariedade, o personagem do médico, as doenças e o desfecho trágico, com o tédio, o fracasso e a morte. A moral do romance é de que homens e mulheres devem se casar virgens, 
mas o entrecho é cômico e libertino, narrado com candidez irônica e recheado de cenas íntimas e picantes, como aparece na sedutora ilustração da capa da terceira edição do romance (Figura 2).

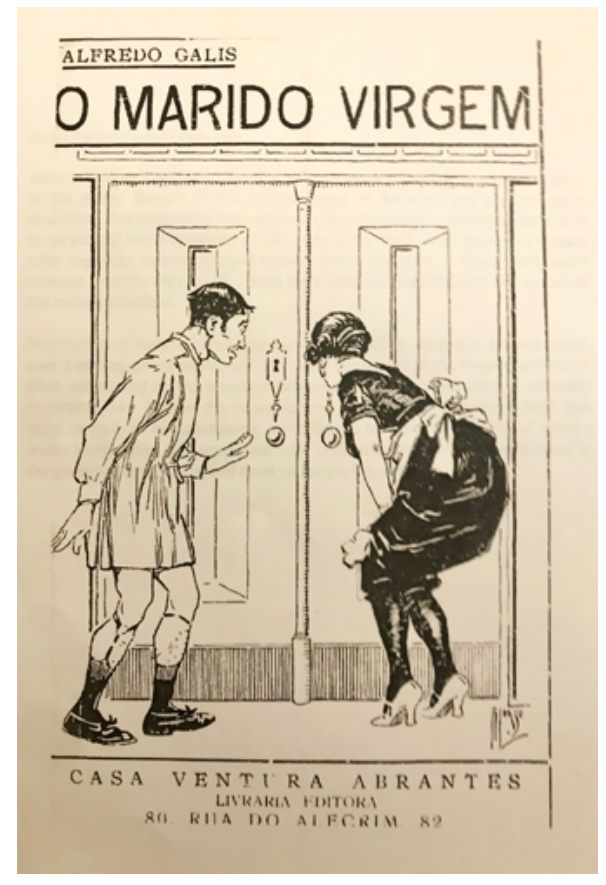

FigurA 2: Capa de O marido virgem, de Alfredo Gallis: voyeurismo e intimidades da alcova. Exemplar Acervo particular.

Em O Sr. Ganimedes, Gallis desbrava o polêmico tema da homossexualidade masculina, tendo tratado da feminina em Sáficas (MENDES, 2021). Apoia-se no mito de Ganimedes para se referir ao homoerotismo e definir o protagonista como um andrógino. Desde criança mimado pela mãe, Leonel tinha vida luxuosa bancada pelo Conde da Lagoa Escura, mas gostava de Liberato, um cantor de fado mal-educado que o pedia para vestir roupas femininas e "dar risadinhas de menina histérica" (GALLIS, 1906, p. 220). Quando o Conde descobre a traição e corta a mesada, Leonel se casa por dinheiro com a viúva rica Lígia, sua antiga preceptora, doze anos mais velha. Seu intuito é manter a relação com Liberato e nunca consuma o casa- 
mento. Como em $O$ marido virgem, a noiva é mais velha do que o noivo. De modo igualmente libertino, Lígia espia por um buraco na parede o marido (de salto alto, meia e liga) tendo relações sexuais com Liberato. Escandalizada, pede o divórcio e viaja para Paris. O romance termina com Leonel nos braços de seu amado, exclamando: "Enfim, livre e só teu!" (p. 231). No proêmio, Gallis garante que sua intenção era combater "a sodomia e o masturbismo" (p. 11). Ele certamente conhecia $O$ Barão de Lavos e Bom-Crioulo, mas se afasta do modelo trágico dos predecessores e privilegia uma atmosfera burlesca e libertina, sem punição ou culpa.

\section{Fantasias eróticas do mundo antigo}

A matriz libertina também inspira um grupo de seis livros eróticos de Alfredo Gallis que têm o mundo antigo como cenário: Voluptuosidades romanas (1891), A amante de Jesus (1893), O sensualismo na antiga Grécia (1894), As 12 mulheres de Adão (1901), A devassidão de Pompeia (1909) e A luxúria judaica (1910). ${ }^{1}$ Outra vez os títulos picantes contrastam com os longos proêmios nos quais Gallis, apoiando-se na leitura de autores greco-latinos, defende a seriedade das obras e censura os excessos sexuais dos antigos. Primeiro apresenta o personagem como um estudioso do século XIX. Cita as fontes e contextualiza-o historicamente. Em seguida, cria uma narrativa erótica baseada no personagem histórico, muitas vezes marcando a transição de registro com um pedido de licença para fantasiar. Em As 12 mulheres de Adão, Gallis chama essa ficção de "episódio histó-

1 A pesquisa não localizou exemplar de Voluptuosidades romanas, $A$ devassidão de Pompeia e A luxúria Judaica. Um anúncio da Livraria Universal, de Porto Alegre, descreveu o primeiro como uma "narrativa curiosa das orgias da devassidão e da libertinagem de toda a espécie que tripudiou na antiga Roma dos Césares” (A Federação, 20 maio 1918, p. 3). 
rico-fantástico" (1927, p. 69). Era o mundo antigo visto pelas lentes libertinas do século XVIII, quando as recém-descobertas ruínas de Pompeia revelaram a distância que separava os antigos dos modernos em matéria de discurso sexual (KENDRICK, 1987). Como em outras obras de Gallis, a seriedade da crônica histórica convive com o princípio libertino (e naturalista) de que o sexo é inconstante, polivalente e dimensão inescapável da vida humana (VARTMAN, 1977).

Desses livros, A amante de Jesus foi o mais conhecido e reeditado. Como prova de seu sucesso, foi a única obra do autor a aparecer em folhetim, no Diário de Notícias do Pará, entre maio e julho de 1894. Gallis se apoia em textos sagrados judaicos e na obra A vida de Jesus (1863), de Ernest Renan (1823-1892), cuja concepção humanizada de Cristo reproduz. Anticlerical, declara estar interessado em investigar o Jesus histórico, e não o mito criado pela Igreja séculos depois de sua morte. As livrarias confirmavam o fundamento científico da obra. Era um "criterioso estudo de Jesus e Maria Magdala, por Alfredo Gallis" (Gazeta de notícias, 06 maio 1894, p. 2). O escritor oferece uma biografia do Cristo, que exalta do começo ao fim. Acompanha Jesus desde o momento que Maria Madalena o vê até a hora de sua morte. Com a publicação, Gallis entrou para a Academia Real de Ciências de Lisboa (Gazeta de notícias, 16 abr. 1894, p. 4). No longo proêmio, o escritor antecipa que o amor de Maria Madalena por Jesus foi platônico. Não havia prova de enlace carnal entre eles, apesar de Gallis considerar o fato provável e normal. Embora o proêmio negue o sexo, o título era escandaloso e libertino, insinuava blasfemo amor carnal e atraía leitores de livros licenciosos (MENDES, 2017). Como faziam com outras obras do autor, as livrarias anunciavam $A$ amante de Jesus como "leitura para homens" (Gazeta de notícias, o4 maio 1894, p. 4).

Em $O$ sensualismo na antiga Grécia, Gallis se apoia no prestígio da civilização grega e do classicismo para validar suas ficções eróticas. No proêmio, admite que "o deboche não tinha limites na pátria de Sócrates”, mas convida o leitor a considerar tais manifestações 
no contexto do culto ao belo de "uma civilização extraordinária" (GALLIS, 1894, p. xv). Considera Roma uma imitação degradada da Grécia. Por isso fala na "devassidão" de Pompeia, em contraste com o "sensualismo" grego, mas eram os mesmos "episódios histórico-fantásticos", chamados aqui de "quadros sensuais" (p. xvii). Na primeira parte, desenvolve o mito de Vênus, a mais óbvia encarnação do erotismo grego. Na segunda, reúne oito contos sobre prostitutas célebres do mundo antigo. "Nos jardins de Epicuro" conta a história de Leontium. Entre colunas jônicas e jardins suntuosos, vemos a mulher se despir e entreabrir com os dedos "os grandes lábios da vulva" (p. 151). Seguem duas orgias com coreografias tipicamente libertinas de voyeurismo e sexo grupal. Para mostrar rigor científico, uma nota de pé de página explica que a expressão "broche do cinto de Vênus" se referia ao "clitóris" (p. 154). O conto termina com a chegada do mestre Epicuro, que exibe incrível vigor físico e possui Leontium "diante de todos", apesar de já contar mais de "setenta janeiros" (p. 143).

Dentre as fantasias do mundo antigo, As 12 mulheres de Adão talvez tenha sido a obra mais elaborada. Parte do pecado original de Eva para criar perfis de mais onze mulheres "pecadoras" através dos séculos, num arco temporal que vai da Roma antiga ao século XIX. Usa vocabulário moderno e classifica as mulheres como "ninfomaníacas" (p. 68). Dos doze perfis, alguns são baseados em pessoas reais, como a romana Messalina (17-48) e a rainha Joana de Nápoles (13261382). Outros perfis são puramente ficcionais. Seguindo a fórmula da série, o capítulo sobre Messalina começa com um estudo histórico que revela seu hábito de ir aos bordéis de Roma para se prostituir. Em seguida, Gallis cria um episódio de uma dessas saídas. A capa da segunda edição, de 1927, capta o objetivo da obra e mostra uma galeria de doze mulheres que se oferecem ao olhar do leitor, com promessas de "aventuras galantes" no interior (Figura 3). Fiel ao espírito 
libertino, algumas mulheres são independentes e ilustradas, como Juliette Récamier (1777-1849), anfitriã dos salões artísticos de Paris no começo do século XIX, e a ficcional Miss Elizabeth Murphy, que preside o "Clube das Solteiras" de Nova York, no mesmo período. Os "pecados" das descendentes de Eva são também atos transgressivos que embaralham as hierarquias patriarcais.

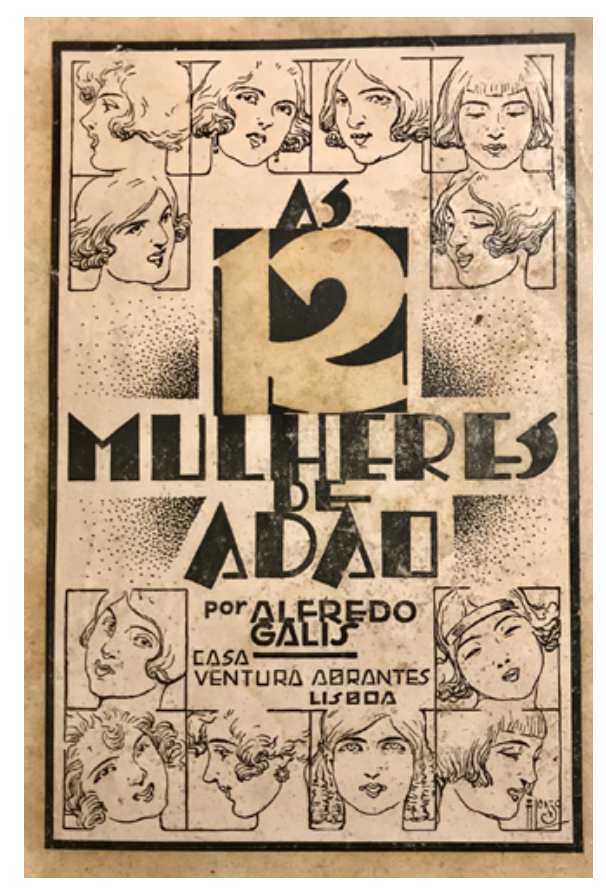

FigurA 3: Capa da segunda edição (1927) de As 12 mulheres de Adão, de Alfredo Gallis. Acervo particular.

\section{As obras de Rabelais}

Rabelais foi a persona mais popular de Alfredo Gallis. Ele apareceu pela primeira vez em 1886, como autor de Volúpias: 14 contos galantes, seu livro mais celebrado, com três edições conhecidas (MOREIRA, 2019). Os anúncios das livrarias destacavam o "apreciado, procurado e adorado Rabelais" (O paiz, 16 out. 1895, p. 8). O reconhecimento do Rabelais renascentista nos circuitos de maior prestígio social facili- 
tava a aceitação dessa literatura. A obra do escritor era o local em que a cultura letrada testava limites de obscenidade e tolerância (MENDES; MOREIRA, 2019). Além de Volúpias: 14 contos galantes, Gallis publicou mais onze livros de contos com o pseudônimo: Cocotes e conselheiros; Os crimes do amor; Gotas de amor; Amorosas: contos galantes; Afrodisíacas: contos que não desmerecem o título do livro; Diabruras de Cupido: contos galantes; Lascivas: contos livres; Libertinas: contos de educação; Lúbricas: contos picantes; Luxúrias para rir: contos alegres e estimulantes; Regras do amor: conselhos íntimos e prescrições para a carne; e Sensuais: contos eróticos. ${ }^{2}$ Lá estão os proêmios, mas em Volúpias admite que não escrevia "para os eruditos nem para os moralistas". Aconselha o leitor a estar só em casa, acender um charuto cubano, tomar um cálice de curaçau e "conservar o chambre largo para o que der e vier" (GALLIS, 1893, p. 9).

Volúpias: 14 contos galantes foi um dos "livros para homens" mais famosos no fim do século no circuito luso-brasileiro. No romance $O$ aborto (1893), de Figueiredo Pimentel (1869-1914), o estudante Mário guarda um exemplar num baú de livros licenciosos. Os catorze contos unem sexo e riso, em cenários contemporâneos ou através de incursões pela história. O conto "Ligurino" é um pioneiro "episódio histórico-fantástico" que usa a orgia da Roma antiga para descrever sexo entre homens. Marcas libertinas aparecem no adjetivo "galante" no subtítulo e no voyeurismo onipresente. O conto "Em flagrante" repete a configuração: pela abertura da porta, um rapaz observa duas moças se acariciando. Terminam num ménage à trois. A atividade sexual é sempre narrada em linguagem galante e erudita, com

2 Das obras de Rabelais, a pesquisa só localizou Volúpias: 14 contos galantes e Cocotes e conselheiros. Não sabemos em que ano foram publicados os outros livros, mas por volta de 1895 estavam todos disponíveis nas livrarias. Em 2011, a editora lisboeta Tinta da China publicou escritos de Rabelais no volume Aventuras galantes, que reúne dois contos de Diabruras de Cupido e mais sete de Volúpias. 
ecos de parnasianismo e decadentismo. A vagina é uma "suntuosa catedral” ou "a celestial mansão" (GALLIS, 1893, p. 100). Destinado aos prazeres físico e mental, Volúpias se apoia nas origens satíricas da pornografia, nos fabliaux medievais, em Boccaccio, Rabelais, Aretino e no romance libertino pré-sadeano. Apesar de conhecida dos homens de letras, a obra do Marquês de Sade é uma aparição rara nos documentos luso-brasileiros do século XIX. Em Volúpias, nada é forçado. Não há culpa ou violência e todos obtêm satisfação.

Embora tenha sido anunciado como continuação de Volúpias, Cocotes e conselheiros tem foco temático mais definido: as relações umbilicais entre o meretrício lisboeta e os altos funcionários da burocracia estatal, eternizado por Eça de Queirós na figura do conselheiro Acácio, n’O primo Basílio. No proêmio, Rabelais alega que seu intuito é expor a hipocrisia e o ridículo desses senhores. Nesse sentido, Cocotes e conselheiros é mais sério do que Volúpias. Faz uso da pornografia para desqualificar figuras de autoridade e não apenas divertir o leitor. Rabelais revela grande conhecimento do submundo lisboeta e diz que testemunhou os fatos que vai narrar. São doze contos sobre o envolvimento de prostitutas com homens públicos idosos e impotentes. O conto "A noite do noivado" faz uso paródico do espaço erótico por excelência - o quarto da lua de mel - para narrar a não consumação do casamento do conselheiro Saturnino Pimenta, de 72 anos, com Gilberta Roland, de 18. Para descrever o fiasco, Rabelais parodia um verso d'O Gigante Adamastor, n'Os Lusíadas: o membro do conselheiro permaneceu "um monstro quedo e mudo, qual junto d'um rochedo outro rochedo” (GALLIS, 1907, p. 69). São histórias satíricas de humilhação masculina (SANTANA, 2007). Possivelmente, por essa razão, não alcançou o êxito de Volúpias.

Das obras de Rabelais que somente conhecemos por registro nos periódicos, Os crimes do amor se destaca por ter sido considerada especialmente atraente pelo comércio livreiro. Como se trata de obra distinta de Volúpias e Cocotes e conselheiros, talvez não fosse de Al- 
fredo Gallis. Devido ao sucesso do pseudônimo como autor licencioso, "Rabelais" agrupava também obras apócrifas ou de escritores de menor fama (MENDES; MOREIRA, 2019). Em 1895, a Livraria do Povo, no Rio de Janeiro, fez propaganda ostensiva d'Os crimes do amor. Sendo o autor o "imortal Rabelais", não era preciso dizer mais nada a favor do livro. Confiante no sucesso, importou 6 mil exemplares de Portugal, sendo que $5 \mathrm{mil}$ foram vendidos para livreiros de outros estados. Com capa colorida, o volume de 400 páginas reunia relatos de "crimes dos reis, rainhas e dos imperadores através dos séculos", num projeto semelhante ao que faria n'As 12 mulheres de Adão. Apoia-se na atração exercida pelas narrativas de crimes e mistério para pressagiar uma "leitura quente", com "mortes, envenenamentos, parricídios, adultérios, incestos, deboches e torpezas praticados desde a mais remota antiguidade até os nossos dias, tendo por causa o amor" (O paiz, 16 out. 1895, p. 8). Segundo a Livraria do Povo, a procura foi grande. Num só dia foram vendidos 300 exemplares (Gazeta de notícias, 21 nov. 1895, p. 1).

\section{Manuais de aconselhamento sexual e matrimonial}

No segundo Oitocentos, o avanço da medicina e das técnicas de impressão promoveu uma proliferação de obras que procuravam ensinar os leitores a ser competentes no ato sexual e na vida íntima (FONTOURA JR, 2019). Alfredo Gallis embarcou nesse lucrativo mercado no começo do século XX. Com o pseudônimo Condessa de Til, publicou $O$ que as noivas devem saber: livro de filosofia prática (1904); e, como Barão de Alfa, assinou $O$ que os noivos não devem ignorar: filosofia prática do amor entre os dois sexos (1907). Tal pedagogia do sexo era detectável em outras obras de Gallis. Em Mártires da virgindade, como vimos, ensina onde comprar pênis de resina em Lisboa e como manejá-lo. O conto "Noite de Núpcias", de Volúpias, funciona como um roteiro da lua de mel para os inexperientes. Em 
Libertinas: contos de educação, e Regras do amor: conselhos íntimos e prescrições para a carne, Rabelais mostra como a pornografia oitocentista aliava entretenimento com a propagação de conhecimento carnal. Esse atributo vinha dos romances libertinos de aprendizado, como o anônimo L'Ecole des filles ou la philosophie des dames (1655) (GOULEMOT, 200o). Como a literatura libertina, os "livros para homens" cumpriam o papel de manuais sexuais não-oficiais, avidamente procurados pelo leitor jovem (MENDES, 2019).

Pelo caminho inverso, os volumes de aconselhamento sexual e matrimonial, incluindo os seriamente científicos, assinados por médicos, podiam circular como "livros para homens". As livrarias às vezes anunciavam os manuais de aconselhamento, sérios ou galhofeiros, nessa categoria. Desde o século XVIII os autores de manuais médicos voltados para a saúde sexual temiam a apropriação dos livros que escreviam como literatura licenciosa (PORTER, 1995). Havia poucas representações do corpo humano e a literatura era a principal forma de disseminação de informações sobre o sexo e as paixões humanas. No Brasil, um manual popular foi Onanismo: só ou a dois, sob todas as suas formas e suas consequências (1901), do médico francês Pierre Garnier (DENIPOTI, 1996). No “Aviso aos Leitores”, defende a seriedade da obra e declara guerra à masturbação, que considera uma inimiga da raça humana. Para Garnier, o casamento era o único espaço legítimo de exercício da sexualidade. Contudo, tanto o título quanto o índice do livro, com capítulos organizados por técnicas de masturbação - "Onanismo pelo esfregar”, "onanismo vulvo-vaginal” e outros sobre as variedades "bucal", "mamário" e "anal" (GARNIER, 1901) -, prometiam veicular precioso conhecimento carnal que podia ser usado para fins que o médico reprovava.

Os livros de Gallis são paródias desses manuais respeitáveis, como o Livro das noivas (1896), de Júlia Lopes de Almeida. No proêmio de $O$ que as noivas devem saber, a Condessa de Til se apresenta como "viúva recatada e afastada do movimento mundano da sociedade" 
(1922, p. 15). Na obra do autor, a viúva é a mulher liberada, como Isabel de Albergaria, em Mártires da virgindade, e Modesta, no conto homônimo de Volúpias. Faz um elogio da idade madura e lamenta ser a beleza física o único valor da mulher para o homem. $O$ que as noivas devem saber foi escrito pensando nas esposas aborrecidas. A narradora feminina remetia às professoras de sexo da literatura libertina, como Teresa Filósofa. Ensina como ser atraentes e submissas para manter os casamentos, mas também dá voz a queixas das mulheres contra o patriarcado e cria um vínculo de sororidade com a leitora. Além de conselhos para as boas relações dos casais, dispensa receitas de beleza para a mulher, como pintar o cabelo, manter a brancura das mãos etc. Para o folhetinista do Diário de Pernambuco, os conselhos da Condessa de Til eram "lições picantes" que arrepiariam "os cabelos de Rabelais" (Diário de Pernambuco, 15 maio 1904, p. 1). Embora escrita por Gallis, essa voz feminina explora um lugar de transgressão e autonomia que, fora da literatura licenciosa, não era permitido às mulheres.

O que os noivos não devem ignorar é a versão masculina do manual. Por se dirigir a homens, o Barão de Alfa é menos galante e mais obsceno do que a Condessa de Til, mas os dois veem a mulher como uma joia frágil que precisa da proteção masculina e defendem uma visão aristocrática e libertina do sexo como arte requintada que exige empenho para se alcançar bons resultados. Como a Condessa critica as mulheres que pouco se esforçam para agradar e segurar seus maridos, o Barão censura os homens que encaram as esposas como "cloacas" e as classificam "no número dos utensílios indispensáveis à satisfação das necessidades do corpo" (1907, p. 17). O livro visa a "indicar como o homem deve compreender e tratar a mulher no capítulo sexual” (p. 24). O Barão inclui dois contos ilustrativos como ensinamento. Em "A noite nupcial de Laura”, ensina aos noivos como tratar uma rapariga na primeira noite. Evita metáforas libertinas como "seta do cupido" e opta pelo neutro e científico "pênis". Mostra 
tudo o que se pode fazer para satisfazer a mulher, incluindo untar os lábios vaginais “com vaselina bórica para lhe tirar o ardor”, após o primeiro sexo (p. 159). Com a desculpa de informar e amparado pela autoridade do "manual científico", o Barão de Alfa oferecia contos mais pornográficos do que as histórias de Rabelais.

\section{Considerações finais}

Conhecer o "pequeno" Alfredo Gallis permite redimensionar a literatura luso-brasileira da Belle Époque e especialmente o naturalismo oitocentista. Ele oferece uma alternativa pouco conhecida ao domínio da França no lucrativo mercado transatlântico de literatura licenciosa no segundo Oitocentos. A atuação de escritores luso-brasileiros no comércio de literatura licenciosa, geralmente com pseudônimos, ainda aguarda investigação aprofundada, mas Alfredo Gallis se destaca como o mais famoso pornógrafo da lusofonia no período. Sua obra de estreia, Volúpias: 14 contos galantes, de Rabelais, foi um livro erótico icônico no fim do século, citado como referência de literatura licenciosa em crônicas de jornal e guardado como um tesouro em baús secretos em casas de família. O aparecimento de Gallis na crônica de João do Rio sobre a Biblioteca Nacional é prova irrefutável de sua importância. São os leitores "imorais" que o procuram, escrevinhando, "com sorrisinhos equívocos, o pedido de Alfredo Gallis" (Gazeta de notícias, o6 fev. 1905, p. 6) - ávidos por literatura erótica, num contexto em que o sexo paulatinamente se torna produto de consumo, à venda nos quiosques, livrarias, teatros e cinematógrafos. Dos romances científicos da série Tuberculose social aos contos eróticos de Rabelais, o nome de Gallis era garantia de entrega do produto.

Aos leitores do período não causava espanto que um escritor naturalista escrevesse pornografia. No fim do século, o naturalismo foi predominantemente apropriado como literatura erótica, indepen- 
dente das boas intenções de Zola ou dos proêmios doutrinadores de Alfredo Gallis. Toda a obra do escritor português, incluindo os "romances científicos" da série Tuberculose social, circulava como "livros para homens" (MENDES, 2017). Gallis é o escritor luso-brasileiro que melhor ilustra a interface entre o naturalismo e a pornografia, que era algo evidente para conservadores (e motivo de repúdio), mas significava boas vendas para livreiros e editores. Tal reposicionamento do naturalismo como "livro para homens" traz à luz uma tradição negligenciada na historiografia canônica da estética: a literatura libertina. A trajetória de Gallis revela que o verdadeiro fundamento da sua obra é o romance libertino e que os proêmios moralizadores eram um verniz "científico" que não convencia ninguém, talvez nem o próprio autor. Como grande parodista, seus romances ligeiros, sensuais e cômicos podem ser lidos como paródias dos sérios “romances científicos” de Zola, Eça de Queirós e Abel Botelho. Daí a importância de se conhecer o "pequeno" Alfredo Gallis, que emerge como um personagem central na história do naturalismo.

RECEBIDO: 28/06/2021 APROVADO: 15/08/2021

\section{REFERÊNCIAS}

ABREU, Márcia (org.). Romancesemmovimento. Acirculaçãotransatlântica dos impressos (1789-1914). Campinas: Ed. UNICAMP, 2016.

ALMEIDA, Aline Cristina Moreira de. O imortal Rabelais: Alfredo Gallis e a literatura pornográfica no Brasil no final do século XIX. 2018. $152 \mathrm{f}$. Dissertação (Mestrado em Estudos Literários) - Universidade do Estado do Rio de Janeiro, Faculdade de Formação de Professores, São Gonçalo, 2018.

ARANHA, Brito. Dicionário bibliográfico português: estudos de Inocêncio Francisco da Silva aplicáveis a Portugal e ao Brasil, continuados e ampliados por Brito Aranha. Vol. 20, $12^{\circ}$. do suplemento. Lisboa: Imprensa Nacional, 1911.

BARÃO DE ALFA (pseud. Alfredo Gallis). O que os noivos não devem ignorar. Filosofia prática do amor entre os dois sexos. Lisboa: Livraria Central, 1907.

BARBOSA, Marialva. História cultural da imprensa: Brasil, 180o-19oo. Rio de Janeiro: Mauad X, 2010. 
BECKER, Colette \& DUFIEF, Anne-Simone (org.). Relecture des "petits" naturalistes. Actes du colloque des 9, 10 \& 11 décembre 1999. Paris: Université Paris $\mathrm{X}$, Centre de Recherches Interdisciplinaires sur les Textes Modernes, 2000.

CONDESSA DE TIL (pseud. Alfredo Gallis). O que as noivas devem saber. Livro de filosofia prática. Porto: Empresa Literária e Tipográfica, 1922.

DE DOMINGO A DOMINGO. Diário de Pernambuco, Recife, 15 maio 1904, p. 1.

DENIPOTI, Claudio. A gloriosa asneira de casar-se: amor e casamento no início do século. Revista de História Regional, v. 1, n. 1, p. 57-86. 1996.

DUARTE, Aline Moreira. Naturalismo, histeria e pornografia em Mártires da virgindade, de Alfredo Gallis. Soletras, n. 30, p. 139-157, jul/dez. 2015.

EL FAR, Alessandra. Páginas de sensação: literatura popular e pornográfica no Rio de Janeiro (1870-1924). São Paulo: Cia. das Letras, 2004.

FONTOURA JR, Antônio José. Pedagogias da sexualidade e relações de gênero: os manuais sexuais no Brasil (1865-1980). Tese (Doutorado em História). Curitiba: Universidade Federal do Paraná, 2019.

GALLIS, Alfredo. Chibos. Lisboa: Livraria Central, 1901. (Tuberculose social I).

GALLIS, Alfredo. As 12 mulheres de Adão. 2a. Ed. Lisboa: Casa Ventura Abrantes, 1927.

GALLIS, Alfredo. O marido virgem: patologia do amor. $3^{\text {a }}$. Ed. Lisboa: Casa Ventura Abrantes, s/d.

GALLIS, Alfredo. Mártires da virgindade: romance patológico. São Paulo: Edições Júpiter, s/d.

GALLIS, Alfredo. Os nefelibatas. Nova Alvorada, Famalicão, n. 3, 1 jun. 1892, p. 133-4.

GALLIS, Alfredo. O Sr. Ganimedes: psicologia de um efebo. Lisboa: Livraria Tavares Cardoso, 1906.

GARNIER, Pierre. Onanismo: só ou a dois, sob todas as suas formas e suas consequências. Rio de Janeiro: Garnier Livreiro-Editor, 1901.

GOULEMOT, Jean-Marie. Esses livros que se leem com uma só mão. Leitura e leitores de livros pornográficos no século XVIII. São Paulo: Discurso Editorial, 2000. 
KALIFA, Dominique; RÉGNIER, Philippe; THÉRENTY, Marie-Ève; VAILLANT, Allain. La civilisation dujournal: Histoire Culturalle et littéraire de la presse française au xix siècle. Paris: Nouveau Monde Editions, 2011.

KENDRICK, Walter. The secret museum: pornography in modern culture. New York: Viking, 1987.

MELlo, Maria Tereza Chaves de. A República consentida: cultura democrática e científica do final do Império. Rio de Janeiro: Editora FGV, 2007.

MENDES, Leonardo. O aborto, de Figueiredo Pimentel: naturalismo, pedagogia e pornografia no final do século XIX. In: MENDES, Leonardo \& CATHARINA, Pedro Paulo (org.). Figueiredo Pimentel, um polígrafo na Belle Époque. São Paulo: Alameda Casa Editorial, 2019, p. 261-349.

MENDES, Leonardo. The Bachelor's Library: Pornographic Books on the Brazil-Europe circuit in the Late Nineteenth Century. In: ABREU, Márcia (ed.), The Transatlantic Circulation of Novels between Europe and Brazil, 1789-1914. London: Palgrave, 2017, p. 79-100.

MENDES, Leonardo. Gays e lésbicas na ficção de Alfredo Gallis. In: MAIA, Helder Thiago; SILVA, Samuel Lima da (org.). Dissidências de gênero e sexualidade: percepções da crítica literária brasileira. Fortaleza: Queer Livros, 2021, p. 155-176.

MENDES, Leonardo. Livros para homens: sucessos pornográficos no Brasil no final do século XIX. Cadernos do IL, Porto Alegre, n. 53, p. 173191, jan. 2016.

MENDES, Leonardo. O retrato do imperador: negociação, sexualidade e romance naturalista no Brasil. Porto Alegre: EDIPUCRS, 2000.

MENDES, Leonardo. Zola as pornographic point of reference in late nineteenth-century Brazil. Excavatio, vol. XXXX, p. 48-62, 2018.

MENDES, Leonardo; CATHARINA, Pedro Paulo. Le naturalisme brésilien au pluriel. Brésil(s). Sciences Humanines et Sociales, n. 15, p. 1-22, 2019.

MENDES, Leonardo; MOREIRA, Aline. Rabelais e a imaginação licenciosa no Brasil oitocentista. Revell, v. 1, n. 21, p. 137-159, jan./abr. de 2019.

MOISÉS, Massaud. A literatura portuguesa em perspectiva. Vol. 3. São Paulo: Atlas, 1994.

MOISÉS, Massaud. A "Patologia Social” de Abel Botelho. São Paulo: Fac. de Filosofia, Ciências e Letras da Univ. de S. Paulo, 1961, p. 22-24. 
MOREIRA, Aline. As matrizes da pornografia de Alfredo Gallis (18591910). Revista Letras, Curitiba, n. 100, p. 133-151, jul./dez. 2019.

PORTER, Roy. Forbidden pleasures: enlightenment literature of sexual advice. In: BENNETT, Paula; ROSARIO, Vernon A. (ed.). Solitary pleasures: The historical, literary, and artistic discourses of autoeroticism. New York: Routledge, 1995, p. 75-98.

RABELAIS (pseud. Alfredo Gallis). Aventuras galantes. Lisboa: Edições Tinta da China, 2011.

RABELAIS (pseud. Alfredo Gallis). Cocotes e conselheiros. $2^{\mathrm{a}}$. ed. Porto: Empresa Literária e Tipográfica, 1907.

RABELAIS (pseud. Alfredo Gallis). Volúpias: 14 contos galantes. $2^{a}$. ed. São Paulo: Livraria Teixeira, 1893.

RIO, João do. Os leitores da Biblioteca. Gazeta de Notícias, Rio de Janeiro, 6 fev. 1905 , p. 2.

SANTANA, Maria Helena. Pornografia no fim do século: os romances de Alfredo Gallis. Portuguese Literary and Cultural Studies, n. 12, 2007, p. $235-248$.

SANTOS, Pedro Rafael Pavão dos. O fado e as artes: um século de cumplicidades e ambiguidades. 2014. 590 f. Tese (Doutorado em História da Arte Contemporânea) - Faculdade de Ciências Sociais e Humanas, Universidade Nova de Lisboa, Lisboa, 2014.

SODRÉ, Nelson Werneck. História da imprensa no Brasil. São Paulo: Martins Fontes, 1983.

THÉRENTY, Marie-Ève. La littérature au quotidien. Poétiques journalistiques au XIXe siècle. Paris: Éditions du Seuil, 2007.

VENTURA, Antônio. “Rabelais”, isto é, Alfredo Gallis, o pornógrafo. In: RABELAIS (pseud. Alfredo Gallis). Aventuras galantes. Lisboa: Edições Tinta da China, 2011, p. 167-174.

\section{MiNicuRRículo}

Leonardo Mendes é professor associado de Literaturas de Língua Inglesa no Departamento de Letras da Faculdade de Formação de Professores da Universidade do Estado do Rio de Janeiro, e professor permanente do Programa de Pós-graduação em Letras da mesma universidade. 
Aline Moreira é mestre em Estudos Literários pela Universidade do Estado do Rio de Janeiro. Atualmente, é doutoranda em Teoria Literária e Literatura Comparada na Universidade do Estado do Rio de Janeiro, e em Literaturas Portuguesa e Brasileira na Universidade da Califórnia, Santa Bárbara. 